\title{
Ativismo digital evangélico e contrassecularização na eleição de Jair Bolsonaro
}

\author{
Evangelical digital activism and counter-secularization \\ in the election of Jair Bolsonaro
}

\section{Carlos Eduardo Souza Aguiar*}

\begin{abstract}
Resumo
A emergência das redes digitais consolida um novo tipo de ativismo religioso no contexto brasileiro que potencializa a chamada onda conservadora. Trata-se de novas dinâmicas que colaboram para a saturação da fronteira entre as esferas do religioso e da política, característica-chave do ideal clássico de secularização. Este artigo aborda o papel do ativismo evangélico conservador digital na eleição presidencial de 2018 , marcada pelo engajamento aberto de igrejas e líderes religiosos na disputa eleitoral, mobilizando suas redes de fiéis, sobretudo em torno de uma pauta moral e de costumes. A pesquisa se baseia na conjunção do uso de dados disponíveis extraídos de fontes secundárias e o estudo exploratório nas redes com base em uma amostra não probabilística obtida por meio de procedimentos de amostragem intencional. Observou-se que o engajamento evangélico eleitoral nas redes é o resultado da consolidação de movimentos conservadores de contrassecularização. Em um contexto de pluralismo, as redes digitais permitem, paradoxalmente, além de uma tomada de palavra e visibilidade de uma série de minorais, uma reação a esses avanços progressistas, com impacto direto na vitória de Jair Bolsonaro.
\end{abstract}

Palavras-chave: Redes digitais. Ativismo religioso. Secularismo. Eleições presidenciais de 2018. Bolsonarismo.

\begin{abstract}
The rise of digital networks consolidates a new type of religious activism that increases the so-called conservative wave in the Brazilian context. These are new dynamics that support to saturate the boundary between the spheres of religious and politics, a key characteristic of the orthodox ideal of secularization. In this paper, we examine the role of conservative evangelical digital activism in the 2018 presidential election, characterized by the open engagement of churches and religious in the electoral dispute, mobilizing their networks of believers, especially around a moral agenda. The research is based on the combination of the use of available data extracted from secondary sources and the exploratory study on the networks based on a non-probabilistic sample obtained through intentional sampling procedures. It was observed that evangelical electoral engagement in networks is the result of the consolidation of conservative countersecularization movements. In a context of pluralism, digital networks allow, paradoxically, in addition to giving voice and visibility to many minorities, a reaction to these progressive advances, with a direct impact on the victory of Jair Bolsonaro.
\end{abstract}

Keywords: Digital networks. Religious activism. Secularism. 2018 brazilian general election. Bolsonarism.

Artigo submetido em 28 de fevereiro de 2020 e aprovado em 24 de setembro de 2020.

* Doutor em Sociologia pela Université Paris Descartes. Professor da FAPCOM. País de origem: Brasil. E-mail: cadu.s.aguiar@gmail.com 


\section{Introdução}

A relevância das tecnologias digitais e em rede e a participação ativa dos evangélicos constituem traços característicos do processo eleitoral de 2018 no Brasil. O deputado federal (1991-2018) e militar reformado Jair Messias Bolsonaro foi eleito Presidente da República com uma campanha baseada quase que exclusivamente em estratégias digitais - com pouquíssimos segundos de propaganda eleitoral gratuita - e o apoio massivo e decisivo dos evangélicos. Grande parte desse apoio se converteu na forma de ativismo digital. Uma postagem pedindo voto para Bolsonaro se apresentava como um imperativo religioso. Assim, tanto instituições como religiosos se engajaram abertamente na disputa eleitoral, mobilizando suas redes de fiéis em torno, sobretudo, de pautas morais. Essa disputa da agenda de costumes agregou diferentes matizes do mundo evangélico e impulsionou uma mobilização voluntária nas redes, configurando-se como uma oposição ao campo que, segundo parte dos evangélicos, representava e simbolizava uma deterioração dos princípios e valores cristãos, o campo petista encabeçado pela candidatura de Fernando Haddad.

Esses religiosos e suas instituições, adeptos à cultura das redes desde os seus primórdios (AGUIAR, 2014), encontram no espaço tecnológico terreno fértil para disseminação desse combate, ungindo como símbolo Jair Bolsonaro. Apesar das redes digitais serem marcadas pela horizontalidade e a consequente multiplicação de pontos de vista - inclusive religiosos - esses atores do mundo evangélico brasileiro optaram por estender sua ocupação midiática da já massiva presença nas mídias analógicas às mídias digitais.

Além de encará-las como ferramentas de proselitismo - como fazem com a televisão e o rádio, disponibilizando vasto conteúdo religioso em websites e canais de Youtube - os evangélicos ocupam esse novo ambiente também como espaço de ativismo para influenciar o debate público. As redes digitais se configuram como esse lugar para a definitiva extrapolação da religião da esfera privada. É também por meio dessas novas tecnologias que a religião busca recuperar a relevância pública 
renegada pelo processo de modernização. Assim, as novas tecnologias são verdadeiros vetores de ocupação da esfera política, o que ficou mais evidente nas eleições presidenciais de 2018.

Essa penetração do religioso, por meio das redes digitais, na esfera política, indica o fortalecimento daquilo que Peter Berger denominou de movimentos de contrassecularização (BERGER, 2001). As eleições de 2018 são o índice, portanto, de que a esfera da política e da democracia, espaços da laicidade por excelência, se confundem cada vez mais com a esfera do religioso.

O problema com base no qual se articula esta pesquisa é o papel desse ativismo digital nos movimentos de contrassecularização. Busca-se compreender como esses movimentos, por conta das redes, participa dos processos políticos, como a eleição de 2018. Para tanto, a pesquisa se baseia na conjunção do uso de dados disponíveis extraídos de fontes secundárias e, sobretudo, no estudo exploratório nas redes com base em uma amostra não probabilística obtida por meio de procedimentos de amostragem intencional. Assim, pretendemos contribuir com o debate acerca do caráter paradoxal do processo de secularização no Brasil, complexificado com as últimas eleições presidenciais.

\section{Secularização e contrassecularização no contexto digital}

Introduzir o problema das mídias no debate sociológico acerca da secularização e seus limites é estabelecer um ponto de vista fértil nessa discussão. O advento das mídias de massa está, tradicionalmente, associado ao processo de secularização porque é igualmente um dos traços da modernização. Por meio dessas mídias teria havido uma intensificação da independência da esfera pública do imaginário religioso, potencializando a secularização como "o processo pelo qual setores da sociedade e da cultura são subtraídos à dominação das instituições e símbolos religiosos" (BERGER, 2011, p. 119). O cinema, o rádio e a televisão colaboram, assim, na progressiva emancipação da vida social, política e cultural. 
Segundo essa definição ortodoxa proposta por Peter Berger, a secularização tem um efeito amplo e categórico na medida em que afeta a totalidade da vida cultural e mesmo a consciência individual. O grande vetor desse processo é a economia moderna, marca do capitalismo industrial, que leva esse ideal para diferentes rincões do planeta, inclusive graças aos meios de comunicação de massa.

A grande questão levantada por Berger e que merece nossa atenção é que, como consequência desse processo, a religião é lançada para a esfera privada, transformando-se em escolha individual. A religião não teria mais a capacidade de estruturar a totalidade da vida social, estando restrita a aspectos específicos da vida, que podem até estar segregados da vida secular. Desse contexto emerge tanto o fim do monopólio das tradições, que não podem mais contar com a submissão automática das populações, como o advento do pluralismo religioso.

Doravante, as religiões devem competir entre si pelas clientelas e competir, inclusive, com agências não religiosas na tarefa de definição do mundo. Como Berger (2011) nos alerta, a situação de pluralismo é uma situação de mercado e os bens religiosos tornam-se bens de consumo. Essa situação pluralista provoca, entre as instituições religiosas, uma necessidade de adaptar seus produtos aos desejos dos consumidores. Com isso, os bens religiosos estão sujeitos às inclinações da moda. Inclinações essas que estão muito atrelados à consciência secularizada dos consumidores. Para Berger, as religiões continuam relevantes apenas nessa área dos problemas privados, e irrelevantes na resolução de problemas econômicos e políticos.

Se os meios modernos de comunicação de massa encontram-se associados à intensificação desse processo, a tomada das mídias de massa pelas religiões e religiosos, e a ocupação cada vez mais intensa das próprias redes digitais nos obriga a renovar a discussão da relação entre as mídias e a secularização. A própria secularização não pode ser considerada de modo exterior ao ambiente midiático no qual esses processos acontecem, o que é causador de profundos paradoxos: 
O aparente paradoxo entre a secularização da sociedade e a visibilidade pública de algumas denominações religiosas pode ser compreendido em termos de midiatização da religião. A inserção nesse processo não só é desigual como também parece ser responsável pelo sucesso ou insucesso midiático - de algumas denominações em relação a outras, algo que se pode observar também em termos de presença nas discussões públicas, práticas sociais e no cotidiano dos fiéis. (MARTINO, 2017, p. 103).

De fato, a nossa atualidade é marcada por uma forte convergência entre religião e mídia, a ponto de assistirmos um processo de midiatização da religião (GOMES, 2010), processo intensificado com o advento das redes. São inegáveis as evidências de que a religião se posiciona cada vez mais no ambiente digital provocando um tipo de experiência que vai muito além da simples disponibilização de conteúdos por novos instrumentos. Essas mediações, caracterizadas por seu caráter tecnológico e reticular, modificam a própria experiência do religioso.

Como esse deslocamento das religiões para as redes não é neutro, algumas tendências observadas na literatura especializada podem ser destacadas nessa religiosidade digital. Essas tendências terão consequências profundas no advento de novas formas de ativismo e proselitismo, com destaque para a questão da multiplicação das visões religiosas e a consequente relativização, ou mesmo crise, dos tradicionais emissores religiosos (AGUIAR, 2014).

De fato, as novas mídias digitais colaboraram na radicalização da multiplicação do campo religioso, dado o acesso a inumeráveis fontes de informação e experimentação, possibilitando infinitas combinações e recombinações. $\mathrm{O}$ monopólio de definição do sagrado é enfraquecido. Se, como destacado por Gianni Vattimo (2011), a época das mídias eletrônicas já pode ser identificada com o processo de multiplicações de vozes ou explosão da palavra, inclusive religiosas, é preciso observar como as novas redes informativas, embora continuem expandindo esse processo, o fazem de forma distinta, incrementando ao extremo as possibilidades de ligações e rearranjos (AGUIAR, 2014).

A autoridade espiritual, defensora de uma verdadeira visão de mundo, se confronta com essa radical multiplicação de vozes, o que faz o digital ser antagonista das hierarquias religiosas, que percebem sua mensagem e sua defesa de uma única e 
verdadeira visão sobre o sagrado num emaranhado infindável de visões alternativas. Nas redes, diferentes atores, não necessariamente ligados à estrutura burocrática das igrejas, disputam as narrativas e participam dos debates. Novos mediadores do religioso forjados por essas tecnologias, como youtubers, blogueiros ou digital influencers são, nesse ambiente, muitas vezes mais relevantes do que pastores, padres ou outros líderes religiosos, sobretudo na orientação de comportamentos.

Esse antagonismo às hierarquias e autoridades religiosas foi uma das características primeiras a ser destacadas na literatura do campo interdisciplinar conhecido como Digital Religion Studies. De modo pioneiro, Højsgaard e Warburg observaram:

\begin{abstract}
Entre outras coisas, essa multiplicação de vozes significa que crenças convencionais e exclusivistas, bem como práticas e organizações autoritárias, estão sendo confrontadas com soluções alternativas, competitivas visões de mundo e sub ou intergrupos de formações. Nesse desenvolvimento interativo de incremento do pluralismo, reflexibilidade, múltiplas possibilidades individuais, novos modos de estruturar e pensar sobre assuntos como realidade, autoridade, identidade e comunidade, estão inevitavelmente emergindo. (HØJSGAARD; WARBURG, 2005, p. 7, tradução nossa).
\end{abstract}

Contudo, como argumentado por Lawther (2009) e Cheong (2012), apesar da internet ser uma mídia com alto grau de relativização de visões religiosas hegemônicas, as religiões tradicionais estão se deslocando maciçamente para esse ambiente tecnológico. Cheong (2012, p. 82, tradução nossa), defendendo uma perspectiva dialética, afirma que a internet "facilita tanto o enfraquecimento quanto o fortalecimento da autoridade religiosa, oferecendo possibilidades de conflito, mas também de compreensão e acomodação".

Assim, o ativismo religioso digital configura-se como uma faceta distinta da midiatização do religioso, afinal para esse ativismo essas novas mídias não são só concebidas como uma ferramenta de proselitismo ou disseminação de mensagem religiosa, mas como um ambiente a ser ocupado a fim de participar da esfera política, ou seja, trata-se de um espaço no qual as hierarquias tradicionais necessitam estar para disputar valor com essa multiplicação de perspectivas. A 
autoridade religiosa tradicional é, nesses casos, remodelada e sustentada por práticas digitais (CHEONG,2014).

O ambiente das redes digitais torna-se, portanto, o lugar das grandes controvérsias contemporâneas e das disputas de valor na esfera política. Há um claro esforço das hierarquias de participar dessas disputas por meio do ativismo digital, afinal, como Castells (2007) destaca, a lógica das redes enfraquece ainda mais contundentemente o poder simbólico dos emissores religiosos tradicionais que estão fora das redes, ou seja, desconectados. Entretanto, a recodificação não devolve a legitimidade desses emissores tradicionais, porque, mesmo assim, seu poder:

[...] fica multiplicado pela materialização eletrônica dos hábitos transmitidos espiritualmente: as redes de pregadores eletrônicos e as redes fundamentalistas interativas representam uma forma mais eficiente e penetrante de doutrinação em nossas sociedades do que a transmissão pelo contato direto da distante autoridade carismática. (CASTELLS, 2007, p. 461).

No caso dos evangélicos, setores fundamentais nas últimas eleições, o fenômeno das redes consolida o que Magali Cunha (2019) chama de desprivatização. Ou seja, esses grupos - até então fechados e atrelados ao quietismo - passam a ingressar cada vez mais na esfera política e partidária, reivindicando a liberdade crítica social da fé, com o claro objetivo de influenciar nos rumos da vida social:

No Brasil da segunda década dos anos 2000, os evangélicos se apresentam "desprivatizados", tendo saído da condição de minoria invisível para uma visibilidade publicizada por meio de estreita relação com as mídias e de participação política com a realização de projetos sociais em parceria com o poder público, com voz nos debates de temas amplos e na mediação de conflitos sociais, com a profissionalização da atuação política e 0 estabelecimento de estratégias. (CUNHA, 2019, p. 5).

O que assistimos no Brasil entre os evangélicos é um processo global de emergência de religiões públicas, como assinalado por José Casanova (1994). Isto é, diferentes tradições religiosas deixam a esfera privada e o domínio da subjetividade e emergem na vida pública, tomando parte de grandes debates e se posicionando 
com uma força social de relevo. Logo, a presença do religioso na esfera política está na ordem do dia e não poderíamos ignorar o papel das redes sociais nesse processo. Por meio das tecnologias digitais, diferentes atores sociais se inserem na esfera política em nome da religião e mesmo as religiões expandem e renovam suas experiências de vida comunitária e suas redes sociais, forjando novos símbolos e significados cuja rápida disseminação no espaço público depende do desenvolvimento de formas inovadoras de produção de conteúdo.

\section{0 ativismo evangélico digital na eleição de Bolsonaro}

As eleições presidenciais de 2018 entraram para a história da política brasileira não somente por marcar o fim da polarização PT e PSDB, mas por terem sido a primeira eleição na qual o papel do tempo de propaganda eleitoral na televisão foi secundário, senão irrelevante. O candidato vencedor, Jair Bolsonaro (PSL), tinha 8 segundos de tempo TV, mas intensas participações em suas redes, como Facebook, Instagram e Twitter. Enquanto isso, o ex-governador de São Paulo, Geraldo Alckmin (PSDB), por exemplo, possuía mais de 5 minutos de televisão e pouca interação orgânica em suas redes, não alcançando nem $5 \%$ dos votos válidos.

Além do papel predominante dessas redes digitais citadas, vale destacar a forte mobilização eleitoral por meio de diferentes listas e grupos de WhatsApp, o que evidentemente dificulta a medição do impacto. Segundo o relatório de uso de redes sociais produzido pelo Datafoha, 70\% dos eleitores de Bolsonaro estavam conectados ao WhatsApp e 31\% repassaram informações sobre política e eleições ${ }^{1}$.

O impacto do WhatsApp é mais orgânico e efetivo dado as características técnicas dessa mídia, afinal, trata-se de redes fechadas que se sobrepõem e complementam os pequenos núcleos da vida cotidiana, como família, trabalho e Igreja. Assim, o Whatsapp se configura como uma comunicação mais rápida, instantânea e que, sobretudo, remete a um senso de proximidade e pessoalidade.

\footnotetext{
${ }^{1}$ Disponível em: https://tinyurl.com/r4upy3k . Acesso em: 01 dez. 2019.
} 
Grande parte desse fluxo eleitoral nessas diferentes redes digitais girava em torno de temas conectados à chamada pauta moral, mobilizados em grande medida também por líderes religiosos tradicionais, sobretudo evangélicos e católicos conservadores, que lançavam mão dessas narrativas a fim de desqualificar os opositores. Esse fluxo informacional colaborou com fortalecimento tanto do sentimento de antipetismo como no repúdio aos partidos tradicionais. Como destacado por Ronaldo de Almeida:

Nas redes digitais, os bolsonaristas divulgaram memes contrapondo às cenas de tortura as de fetos abortados, como forma de neutralizar a investida também moral dos progressistas. Associado a essa linha de discurso, Bolsonaro abraçou a pauta dos costumes, articulando-se, de um lado, com uma base parlamentar evangélica e, por outro, com o eleitor evangélico, que sempre foi sensível às questões relativas ao corpo e aos comportamentos. Seu discurso foi contrário a praticamente todas as mudanças concernentes à sexualidade, gênero e reprodução das últimas décadas. É contra o aborto e as causas lgbt. Combateu a chamada "ideologia de gênero", maior espectro que assombra a população mais conservadora, gerando uma espécie de pânico moral. "O pt é uma ameaça, um perigo", ouviu-se dos que votaram em Bolsonaro, principalmente entre os evangélicos. (ALMEIDA, 2019, p. 205).

Essa participação religiosa, sobretudo evangélica, consolida uma longa e crescente participação desses religiosos na esfera política (CUNHA, 2017), transformando as igrejas evangélicas em verdadeiras máquinas eleitorais (PRANDI; SANTOS; BONATO, 2019). Além de um apoio formal, como no caso dos líderes da Igreja Universal do Reino de Deus e da Igreja Internacional da Graça, algumas personalidades do mundo evangélico participaram de modo mais ativo por meio de estratégias de ativismo digital, gravando vídeos ou fazendo postagens nas redes sociais, material que evidentemente era disseminado pelas redes de apoiadores do candidato vencedor.

Dentro do eleitorado religioso, o público evangélico se destaca como fundamental para a vitória de Bolsonaro, afinal, foi entre eles que o militar reformado conquistou uma maior vantagem, cerca de 11 milhões de votos de diferença, frente a uma ligeira vantagem entre católicos de apenas 160 mil votos, segundo estimativas projetadas com base na pesquisa do Datafolha divulgada às 
vésperas do segundo turno ${ }^{2}$. Ou seja, dentro do público evangélico, Bolsonaro conquistou $70 \%$ dos votos válidos, diferença muito maior do que a conquistada entre católicos, onde a onda pró-Bolsonaro foi bem menos significativa.

O próprio Bolsonaro, já no exercício de seu mandato, fez inúmeras declarações destacando a importância evangélica na sua vitória. Por exemplo, quando participou da celebração dos 40 anos da Igreja Internacional da Graça comandada por R. R. Soares, Bolsonaro declarou: "vários setores da sociedade me apoiaram, várias denominações religiosas fizeram o mesmo. O setor evangélico foi muito presente há dois anos". No mesmo evento, o pastor reconheceu esse apoio, sobretudo por conta da posição enfática de Bolsonaro contra a chamada "ideologia de gênero", e lembrou de um encontro dos dois após o primeiro turno: "A única coisa que eu quero é que o senhor ganhe para essa mentira não prevalecer. Que não tem coisa mais linda que ver um menininho dizendo que é homem e uma menininha dizendo que é mulher. É isso que Deus fez"3.

A fala de R.R. Soares ecoa todo um imaginário forjado na época das eleições pelo ativismo digital. Parte significativa do material difundido na época, muitas vezes de origem desconhecida e disseminada de forma anônima e que se enquadra nas chamadas Fake News, era direcionada a melindrar o público religioso, demonizando o principal oponente. As mais célebres e disseminadas Fake News, circuladas sobretudo pelo Whatsapp, foram aquelas ligadas ao chamado "kit gay", suposto material escolar de educação sexual distribuído pelos governos do PT que incentivaria crianças a comportamentos homossexuais, e a mamadeira com bico em formato de genitália masculina, suposto aparato que teria sido distribuído em creches paulistanas pelo então prefeito Fernando Haddad. Bolsonaro, em menor grau, também foi alvo de Fake News religiosa, como a informação segundo a qual ele propunha a retirada do título de padroeira do Brasil de Nossa Senhora Aparecida4.

\footnotetext{
${ }^{2}$ Disponível em: https://tinyurl.com/vr3qrcg. Acesso em: 01 dez. 2019.

${ }^{3}$ Disponível em: https://tinyurl.com/yb8po5lq. Acesso em: 24 fev. 2020.

${ }^{4}$ Disponível em: https://tinyurl.com/y7y9ljuy Acesso em: 20 dez. 2020.
} 
Cronologicamente, essa adesão à candidatura de Jair Bolsonaro se deu de maneira mais contundente com a entrada oficial de Fernando Haddad na disputa, em 14 de setembro de 2018, substituindo o ex-presidente Lula que fora impedido de disputar por conta da lei da ficha limpa. Até então, Bolsonaro não era colocado como o "candidato oficial" das diferentes Igrejas; inclusive outros evangélicos estavam na disputa, como Cabo Daciolo e Marina Silva. Foi a entrada de Haddad, que rapidamente subiu nas pesquisas, que impulsionou essa adesão. A demostração de força eleitoral de Haddad, que teve capital eleitoral transferido de Lula, provocou um alvoroço nas forças oposicionistas, fazendo com o que os apoios se concentrassem no candidato mais bem colocado até então e que acabara de sofrer um atentado à faca na cidade de Juiz de Fora, situação que colaborou na humanização de Bolsonaro.

A partir dessa data, diversos líderes nacionais e regionais de Igrejas evangélicas começaram a declarar apoio ao candidato, ocupando sobretudo as redes sociais para, ao mesmo tempo, demonizar o candidato petista e destacar que Bolsonaro seria o candidato mais adequado para conter essa ameaça. O objetivo principal não era disseminação dos pontos programáticos de Bolsonaro, mas criar uma atmosfera de pânico moral que a vitoria petista representaria.

Jair Bolsonaro, apesar de se declarar católico, é casado com uma evangélica e há algum tempo fazia acenos a esse público, encampando a defesa da pauta moral juntamente com a bancada evangélica, tendo sido, inclusive, batizado pelo pastor Everaldo, ex-candidato a presidência, nas águas do rio Jordão. Apesar de sua personalidade rude e bélica, Bolsonaro se converteu no símbolo da moralidade cristã. Curiosamente, o sucesso de suas estratégias de sedução foi inversamente proporcional à moderação dos seus discursos. Apesar dos seus sucessivos mandatos de deputado federal, se posicionou como um político outsider capaz de combater as elites políticas corrompidas. Com seu slogan, "Brasil acima de tudo, Deus acima de todos”, Bolsonaro se credenciou como o candidato capaz de conduzir essa luta contra a degradação moral. Os eleitores evangélicos de Jair Bolsonaro não viram no 
candidato a imagem clássica do político, mas o homem comum - desprovido do arcabouço midiático analógico dos personagens tradicionais e capaz de encampar essa luta moral, atraindo, assim, o eleitor por meio da linguagem e ideário antipolítico.

Outro evento fundamental dessa adesão evangélica foi a manifestação \#EleNão, organizada nacionalmente em repúdio ao candidato a presidente Jair Bolsonaro em 30 de setembro de 2018. Ao contrário do que era esperado, após essas grandes manifestações que envolveram cidades de todo o país, houve um aumento considerável nas intenções de voto em favor de Bolsonaro e um fortalecimento do bolsonarismo.

O ativismo dos bolsonaristas, inclusive parte do público evangélico, fez circular nas redes sociais inúmeras imagens (verdadeiras, falsas ou manipuladas) associando o campo opositor a Bolsonaro - sobretudo o campo dos petistas e da esquerda - à devassidão moral, sexual, ao chamado feminismo radical, ao ateísmo, à improdutividade, ao comunismo, à pedofilia etc. Ou seja, um conjunto de condutas e valores foi associado ao petismo, todos eles considerados pelo ativismo evangélico como ameaçadores dos alicerces da moral cristã tradicional.

A imagem abaixo revela essa operação de separação radical entre dois campos antagônicos, estigmatizando o campo opositor. Perante esse antagonismo, o "cidadão de bem", em particular o eleitor evangélico, precisa escolher seu lado. A circulação de imagens como esta abaixo tem como função fornecer símbolos de um combate moral comum, capaz de agregar e promover uma comunhão de grande parte dos evangélicos conservadores brasileiros e que acaba tendo consequências eleitorais significativas. 
Figura 1 - Montagem \#elenão vs \# elesim

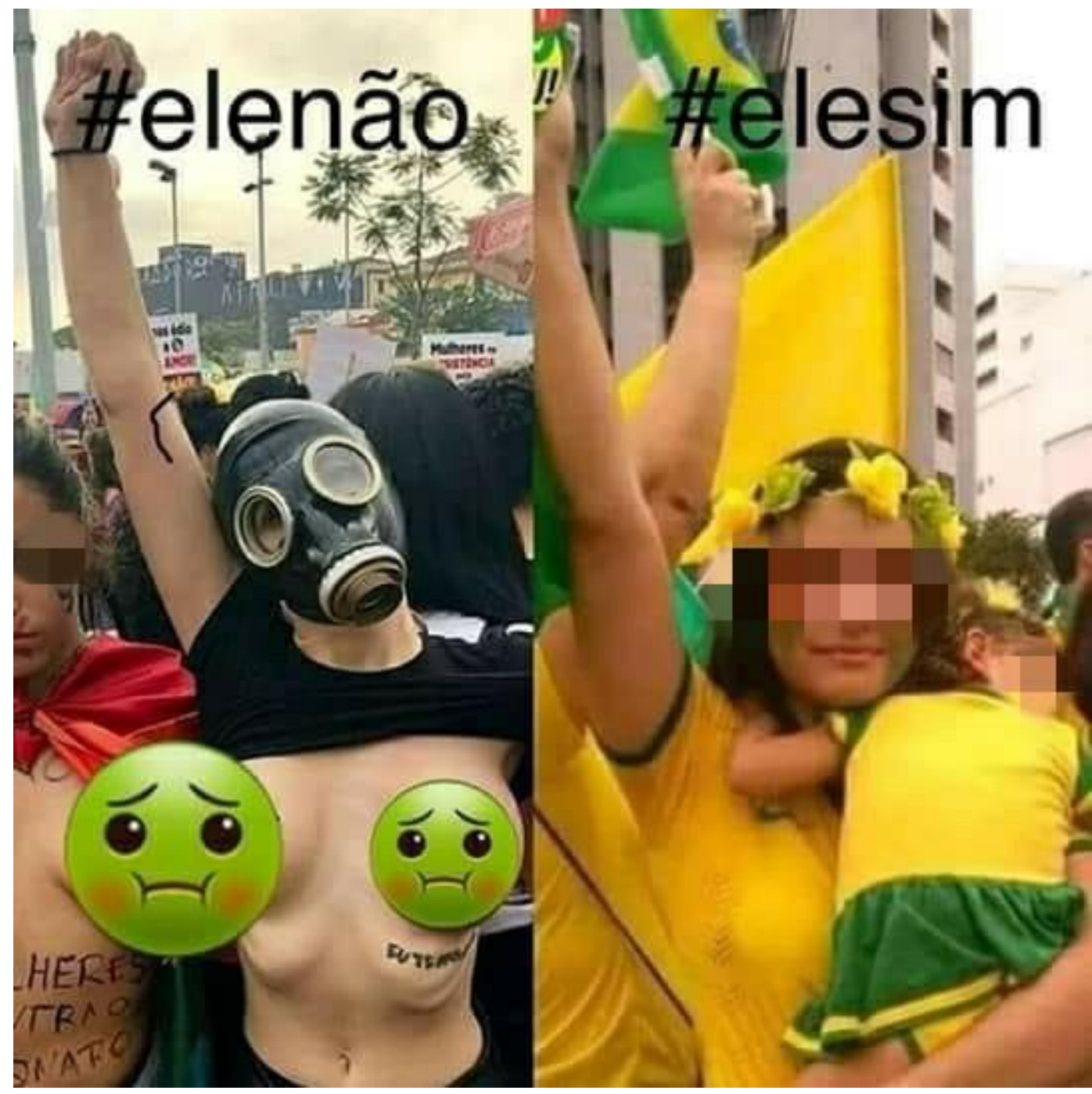

Fonte: https://web.facebook.com/

Com a definição do segundo turno entre Bolsonaro e Haddad, a pauta religiosa se consolidou definitivamente e grande parte da discussão girou em torno dos valores cristãos. $\mathrm{O}$ candidato petista buscou enfraquecer a ideia de que ele era antirreligioso realizando atos políticos em Igrejas, declarando-se cristão, encontrando-se com lideranças religiosas, alterando pontos sensíveis do programa de governo. Além dessa estratégia formal da candidatura, grande parte da militância anti-bolsonaro se lançou em um ativismo nas redes buscando demonstrar as incoerências entre os valores cristãos e a personalidade de 
Bolsonaro, utilizando, inclusive, de versículos bíblicos. Enfatizou-se muito, por exemplo, que alguém favorável à tortura não poderia simbolizar os valores cristãos.

Para nos aproximarmos desse fenômeno do ativismo religioso e eleitoral de modo mais focado, conduzimos uma pesquisa exploratória nas redes com base em uma amostra não probabilística obtida por meio de procedimentos de amostragem intencional. Delimitando a análise exploratória na plataforma Youtube, escolhemos cinco atores do mundo evangélico: o líder regional Wesley Thomas, pastor evangélico da Igreja Nova Aliança com Deus de Rondônia; Silas Malafaia, liderança nacional evangélica ligado à Assembleia de Deus; Marco Feliciano, pastor da igreja Catedral do Avivamento e deputado federal; José Wellington; ex-presidente da Convenção Geral das Assembleias de Deus no Brasil; Cláudio Duarte, pastor representante da Igreja Batista Nacional. As atividades desses líderes referentes ao período eleitoral de 2018, entre 16 de agosto e 28 de outubro, foram mapeadas, observadas e descritas.

Excetuando o primeiro pastor, todos os demais são líderes nacionais de grande visibilidade e que possuem aparatos mediáticos consideráveis. No entanto, esses líderes não se eximem de ocupar esses espaços das redes, inclusive para campanha política. Facebook, Instagram, Youtube e outras arquiteturas informacionais estão integradas em seus trabalhos pastorais.

Comparado aos demais, o pastor W. Thomaz tem uma presença modesta no Youtube, utilizando o perfil de sua Igreja 5 como espaço de divulgação, além de outros vídeos de filmagens amadoras disponibilizadas pelos próprios fiéis. Em um desses vídeos, filmado em um culto, o pastor age como cabo eleitoral que executa uma performance para estar nas redes digitais. Ou seja, percebe-se esse ativismo digital mesmo em lugares mais afastados dos grandes centros populacionais e econômicos do país, como, no caso, Rondônia. Para o pastor, os evangélicos precisam dizer "não à ideologia de gênero" e não "a tudo que acaba com a família", de modo que a candidatura de Bolsonaro se revela a mais adequada na eleição

${ }^{5}$ Disponível em: https://www.youtube.com/channel/UC-sTJFJQ7_H8fn4-sq2JOxw. Acesso em: 20 dez. 2020. 
presidencial. O pastor deixa claro que seu compromisso é com o cristianismo e ameaça: "...do mesmo jeito que eu estou falando aqui bem de vocês, eu volto para cá de novo, então em nome de Jesus, abrace esse povo, ame esse povo..."6.

Já o perfil de Silas Malafaia no Youtube7 é um dos mais populares entre os líderes evangélicos, com mais de 1 milhão de inscritos e com inserção diária de vídeos, a maioria deles gravados para esta plataforma. No período analisado, foram publicados 57 vídeos, sendo 31 com as eleições de 2018 como assunto principal. Nos vídeos de Silas Malafaia, a mesma missão é posta, ou seja, o combate àquilo que acaba com a família e que é simbolizado, em um primeiro momento, nos candidatos de esquerda e, em seguida, em Fernando Haddad. O combate é duro porque o candidato do PT, mesmo representando tudo aquilo que derreteria as bases da vida cristã, é sedutor, pois, segundo o pastor, utiliza das mesmas táticas do demônio para enganar o cristão. No entanto, alerta o pastor, "o povo brasileiro, em nome de jesus, vai botar Haddad e o PT para correr, eles não enganam mais ninguém, você não pode deixar ser enganado"8.

E nessa missão de derrotar o PT, Bolsonaro surge como o ungido. Com discurso politicamente coerente, Malafaia enumera uma série de atributos que justificam o voto no candidato Bolsonaro: "Olá, povo abençoado do Brasil, analise o que eu vou falar: por que você deve votar em Bolsonaro para presidente da nossa nação...". Em linhas gerais, é Bolsonaro o mais adequado para cumprir essa missão de derrotar a "esquerda que destruiu o Brasil”, pois é necessário “amar a nação”, e ser alguém de "vida limpa" e "a favor da vida”, todos atributos possuídos por Bolsonaro9.

Segundo esses religiosos, trata-se de uma missão na qual os evangélicos precisam se posicionar, e assim são cotidianamente cobrados, como ressalva Marcos Feliciano em vídeo gravado no hospital depois do episódio da facada: “Eu,

\footnotetext{
${ }^{6}$ Disponível em: https://www.youtube.com/watch?v=kq8YwouG12I. Acesso em: $01 \mathrm{dez} .2019$.

${ }^{7}$ Disponível em: https://www.youtube.com/channel/UCEosIUVXeGLIFtyp9ZfnGug. Acesso em: 20 dez. 2020.

${ }^{8}$ Disponível em: https://www.youtube.com/watch?v=03GO1N4uT4A. Acesso em: 20 dez. 2020.

${ }^{9}$ Disponível em: https://www.youtube.com/watch?v=4uBxAl-rPyw. Acesso em: 01 dez. 2019.
} 
como pastor e como pessoa pública, sou cobrado diariamente, Bolsonaro, sobre quem é meu candidato a Presidente da República, então estou aqui para falar como pessoa física, eu, Marco Feliciano, voto em Jair Bolsonaro...". Feliciano, que fora colega de Bolsonaro na câmara dos deputados, foi um dos apoiadores de primeira hora do candidato e possui vários vídeos o apoiando, tanto em sua página ${ }^{10}$, que possui quase 250 mil inscritos, quanto em outros canais da esfera evangélica. No mesmo vídeo do hospital, o próprio Bolsonaro busca estabelecer essa conexão com os evangélicos apontado que Feliciano é um antigo parceiro "na defesa da família, da criança em sala de aula, contra o aborto, pelos bons costumes e contra a ideologia de género" ${ }^{11}$.

Durante o processo eleitoral, Jair Bolsonaro foi se consolidando como o candidato ideal que se encaixa dentro do perfil desejado pelas lideranças evangélicas. Esse é o posicionamento de José Wellington, líder da Assembleia de Deus $^{12}$ que, às vésperas do primeiro turno, participou de uma celebração na qual um vídeo de Bolsonaro o parabenezindo-o pelo aniversário de seu casamento foi exibido e no qual o candidato aponta as convergências dele com os anseios evangélicos, sobretudo na "defesa da família, no respeito às crianças, na luta contra o aborto, contra as drogas”. Para José Wellington, a orientação primordial é “não votar à esquerda”, pois “não podemos deixar o país cair na mão dessa gente outra vez”. Assim, ao direcionar uma mensagem ao candidato em sua Igreja, afirma: “...o senhor fala nosso idioma, o senhor fala aquilo que os evangélicos gostariam de ouvir, e nós estamos certos que com o apoio dos evangélicos o senhor cumprirá seus compromissos junto conosco [...] o mais importante é o número 1, o Presidente da República”13.

Dada essa convergência explicitada tanto pelo candidato quanto pelos líderes, é dever dos evangélicos votar em Bolsonaro, conforme destacado por Cláudio Duarte: “...domingo, dia 28, Bolsonaro 17 para presidente da

\footnotetext{
${ }^{10}$ Disponível em: https://www.youtube.com/user/prmarcofeliciano. Acesso em: 20 dez. 2020.

${ }^{11}$ Disponível em: https://www.youtube.com/watch?v=d5cjcxSXOto. Acesso em: $01 \mathrm{dez} .2019$.

${ }^{12} \mathrm{O}$ pastor utiliza o canal de sua Igreja no Youtube para divulgar suas pregações. Disponível em:

https://www.youtube.com/c/tvadbelem. Acesso em: 20 dez. 2020.

${ }^{13}$ Disponível em: https://youtu.be/IXbJL6zyWII. Acesso em: 01 dez. 2019.
} 
república..."14. O pastor Duarte é outro líder muito popular no Youtube, cujo canal tem mais de 1 milhão de inscritos ${ }^{15}$ e foi um dos grandes entusiastas da candidatura Bolsonaro, tendo inclusive participado de uma live com o candidato e Silas Malafaia dois dias antes do primeiro turno. Nessa ocasião, o pastor ressaltou que "o movimento de esquerda tem como função descaracterizar a família” e escolheu Bolsonaro porque, assim como o candidato, ele é "a favor da família e contra a erotização infantil16”.

Em geral, em todos os vídeos analisados os discursos se concentram em delimitar dois campos opostos, um que representa a devassidão moral, simbolizada pelo PT e o campo encabeçado por Jair Bolsonaro, comprometido no combate dessas ameaças. É interessante observar que os argumentos mobilizados pelas lideranças religiosas evangélicas na campanha pelo voto em Bolsonaro consistem em posições tradicionalistas referentes à família e à moral sexual, não aprofundando na discussão acerca da agenda econômica liberal ou de outras pautas históricas do conservadorismo político.

Como já observado, esse ativismo mais direto, no qual lideranças se posicionam claramente em favor de um candidato e se colocam como "cabo eleitoral", utilizando as redes sociais digitais como campo de disseminação, somase ao ativismo anônimo dos memes, das correntes, da demonização do campo opositor, utilizando inclusive Fake News, forjando uma atmosfera muito próxima daquilo que Jean Baudrillard (1997) chamava de Hiperrealidade, isto é, um contexto de desinformação generalizada no qual a própria fronteira entre o verdadeiro e falso é abolida. Cabe ressaltar que esse ativismo analisado é uma das peças de um cenário eleitoral complexo e de múltiplos fatores, não podendo ser resumido a fácil narrativa segundo a qual o candidato Jair Bolsonaro foi eleito por conta das Fake News e desse contexto de desinformação.

\footnotetext{
${ }^{14}$ Disponível em: https://www.youtube.com/watch?v=PydoqKNLHsU. Acesso em: 01 dez. 2019.

${ }^{15}$ Disponível em: https://www.youtube.com/user/pastorclaudioduarte. Acesso em: 20 dez. 2020.

${ }^{16}$ Disponível em: https://www.youtube.com/watch?v=cxXJOzhjkfY. Acesso em: 20 dez. 2020.
} 
Esse ativismo religioso nas redes, que atinge a esfera eleitoral, é uma das tendências dessa "religião digital". Assim, se as redes provocam uma crise da autoridade e saturação das hierarquias, como destacado na literatura, isso evidentemente provoca uma reação que impele essas lideranças a habitar e lutar por espaço nas redes digitais.

\section{Ativismo religioso digital e a questão do secularismo brasileiro}

Com as eleições de 2018 e todo esse contexto de redes e de tecnologias digitais, a religião se insere no centro do debate contemporâneo. As redes digitais, que foram idealizadas como um espaço democrático e portador de diversidades, facilitam igualmente o advento de nichos comunitários. Assim, ao mesmo tempo em que as redes permitem uma forma de mobilização horizontal que possibilita minorias de toda ordem - grupos feministas, grupos LGBTQI+, grupos étnicos etc. - a se mobilizarem pela conquista e garantia de direitos fundamentais, elas também possibilitam uma reação de religiosos e segmentos confessionais conservadores que as utilizam para disseminar preceitos morais criando uma sensação inédita de intolerância e hostilidades. Desse modo, a esfera do político e da democracia se confunde cada vez mais com a esfera do religioso, dado o conflito entre forças da secularização e religiosas:

Num contexto sociocultural pluralista e formalmente democrático, grupos laicos e laicistas têm intensificado sua luta para obter e assegurar o reconhecimento de seus direitos humanos, sexuais, sociais e reprodutivos. Com tal propósito, têm reagido às aspirações, propostas e ações de seus adversários religiosos, recorrendo, fundamentalmente, à defesa da laicidade estatal contra interferências religiosas na educação, na saúde, no corpo, nas pesquisas científicas, nas políticas públicas, no ordenamento jurídico-político e nos órgãos estatais. De outro lado, em contraste, católicos e evangélicos têm recrudescido seu ativismo religioso, político e midiático para ampliar a ocupação religiosa do espaço público, influenciar a esfera pública e estatal, promover sua moralidade cristã tradicional e tentar estendê-la ao conjunto da sociedade por meio de lobby e da participação na política-partidária. (MARIANO, 2011, p. 252). 
Esse conflito vai ao encontro daquilo que Berger chamou de contrassecularização, movimento que acontece justamente no interior dos dinamismos da modernidade secularizante: "Com certeza, a modernização teve alguns efeitos secularizantes, em alguns lugares mais do que em outros. Mas ela também provocou o surgimento de poderosos movimentos de contrassecularização" (BERGER, 2001, p. 10).

São justamente as redes digitais que permitem a consolidação de movimentos conservadores de contrassecularização, afinal, para as Igrejas e líderes religiosos, a principal função da internet é o seu poder de disseminação sem precedentes. Disseminação não apenas do conteúdo institucional, mas sobretudo de preceitos morais. Incrementando a complexidade, observa-se igualmente uma contrarreação de religiosos ditos progressistas que buscam, também por meio das redes digitais, defender uma mediação entre a fé e as pautas progressistas, e que nas eleições de 2018 se posicionaram claramente contra Jair Bolsonaro.

Se as redes digitais inegavelmente tornam mais visível o pluralismo cultural e a luta pelos direitos, elas também permitem uma forma de mobilização inédita de grupos conservadores que, antes de se agregarem em torno de uma instituição, se agregam em torno de uma reação, muitas vezes dispersos no território. Assim, as redes evidenciam não a crise da secularização, como queriam certos analistas ao refletirem sobre o ressurgimento do religioso na modernidade tardia, mas a sua reconfiguração, o incremento da complexidade das suas inter-relações, afinal como nos alerta Danielle Hervieu-Léver (1999), a secularização não é sinônimo da perda da religião no mundo moderno. Não podemos confundir a secularização com o desaparecimento da religião na modernidade, em particular na modernidade tardia, contexto das redes digitais.

É necessário, portanto, analisar a questão do secularismo diante desse avanço evangélico na esfera política e eleitoral sob outra perspectiva e não simplesmente como a quebra da separação radical entre Estado e Igreja com o reaparecimento da religião na esfera política. Aqui, a contribuição de Charles 
Taylor (2012) é fundamental. Para o filósofo canadense, o centro do debate não se concentra apenas na exclusão da religião da esfera política, trata-se de uma exigência muito mais complexa. Assim, o autor estabelece alguns critérios. O primeiro presume que ninguém possa ser constrangido no domínio da crença ou da religião; o segundo princípio presume que deva existir uma igualdade entre pessoas que professam diferentes credos ou mesmo nenhum credo; o terceiro vislumbra que todas as famílias religiosas devem ser ouvidas no processo de definição do que é sociedade; por fim uma quarta meta seria a tentativa de buscar uma harmonia entre essas diferentes perspectivas religiosas na medida do possível.

O que esse conjunto de metas indica é que o secularismo não está tão relacionado à ligação entre Estado e Igreja, mas em como o Estado responde a um contexto de diversidade religiosa. Trata-se de uma neutralidade estatal que evite tanto o favorecimento de uma determinada religião como o desfavorecimento de um grupo religioso, potencializando um contexto de múltiplos secularismos (STEPAN, 2010).

Analisar o ativismo digital evangélico nas eleições brasileiras sob o prisma do debate acerca do secularismo representa um ponto fértil de discussão. É repudiando esses critérios de secularismo e a neutralidade do Estado, e não apenas a separação entre Estado e Igreja, que os grupos conservadores ressurgem e ganham terreno, mobilizando-se, inclusive, no ambiente digital. Como destacado por Magali Cunha (2019, p. 16), “os ativistas evangélicos conservadores têm noção do lugar das mídias na conquista de espaço e de visibilidade no espaço público e dominam as técnicas e métodos de alcance das mídias”.

Como ficou claro no processo eleitoral, essa onda conservadora ocorreu porque transformações culturais de fundo tornaram-se a realidade brasileira, como a ampliação dos direitos civis de minorias. Esse ativismo visa, portanto, influenciar no resultado eleitoral e proteger pela capacidade de influência nas políticas de estado a chamada "família tradicional", resgatando os valores morais cristãos que outrora dominavam a vida brasileira e que se encontram ameaçadas pelo ativismo 
progressista, sobretudo pelos movimentos feministas, antirracistas e LGBTQI+. Em suma, é o repudio ao ideal de secularidade, especialmente o quesito da neutralidade do Estado, o grande motor de emergência, consolidação e ampliação desse ativismo evangélico conservador (MARIANO, 2016).

Como indica a inegável presença nas redes de instituições, grupos autônomos e líderes religiosos, um dos espaços fundamentais dessa militância é o ambiente digital. Antes de se configurarem como meras ferramentas de proselitismo, essas tecnologias forjam um ambiente a ser ocupado para a defesa de uma moral ameaçada. No limite, na perspectiva evangélica, proselitismo não é diferente de ativismo político.

Assim, quanto mais intenso o pluralismo, maior a necessidade de oferecer laços fortes de engajamento em torno de um combate comum, de modo que "A dimensão da comunicação como interação-comunhão fica potencializada. A sociabilidade promovida pelas mídias digitais facilita a sociabilidade cristã e a evangelização" (CUNHA, 2017, p. 31). Assim, é por meio das redes que a religião e os religiosos podem agregar um coletivo em torno de um combate, normalmente contra ideias seculares, grupos de pessoas dispersas no território e não necessariamente ligadas a uma igreja específica.

O digital é um espaço discursivo e icônico de argumentação, de influência e de incitação no qual os diferentes atores religiosos podem se exprimir e buscar inflexionar as práticas de uma instituição ou mesmo de um país. O que está em jogo, bem ao gosto do ideal comunitário ou tribal do qual fala Michel Maffesoli (2002), é o compartilhamento de um gosto comum, muitas vezes de forma efêmera, difusa e pontual, como no caso de um processo eleitoral. Não se trata de um ativismo político tradicional, mas de uma transfiguração do político que, ainda segundo Maffesoli (2002, p. 154), é "consumada quando o ambiente emocional toma o lugar do racional, ou quando o sentimento substitui a convicção”. 
No caso das eleições de 2018, o que forjou esse ambiente emocional foi a reação a uma agenda dita progressista, induzido muitas vezes por falsas informações disseminadas pelas redes. Diferentes eleitores evangélicos, não necessariamente ligados à hierarquia religiosa e imbuídos de um sentimento de indiferença à política tradicional, se congregaram pelas redes sociais digitais em nome dessa convicção de que a ação era necessária para frear o desmoronamento iminente dos alicerces dos valores cristãos, avaliação muito mais emocional do que racional. Antes de indagar se os eleitores acreditavam de fato nas Fake News, como o "kit-gay" ou a mamadeira erótica, nos cabe compreender que compartilhar um desses memes tinha uma dimensão quase religiosa, pois reforçava os laços e a subjetividade do grupo. Jair Bolsonaro, antes de indutor desses processos, foi o emblema em torno do qual se congregou essas redes, uma escolha que simbolizava o repúdio à representação política moderna tradicional, servindo, ao mesmo tempo, para canalizar sentimentos e paixões comuns.

\section{Conclusão}

Ilumina-se a surpreendente eleição presidencial de 2018 pela tríade mídia, religião e poder. Esse foi um processo caracterizado por um enorme engajamento religioso, sobretudo por meio das redes digitais, e que se mostrou efetivo. Tanto instituições como religiosos se engajaram abertamente na disputa política e eleitoral, por meio de uma mobilização inédita de suas redes de fiéis, além de um engajamento dos próprios evangélicos em um movimento horizontal. O bolsonarismo, assim, impulsionou uma verdadeira onda religiosa e conservadora, consolidando um processo de tomada da esfera política. Trata-se de movimentos de contrassecularização, porque foram articulados não em nome de pontos programáticos da agenda política de Jair Bolsonaro, mas, sobretudo, como uma reação a uma tomada de palavra e uma visibilidade pública inéditas de diferentes minorias, possibilitadas paradoxalmente pelas próprias redes. 
Esse ativismo é uma das muitas faces do impacto do digital no mundo da religião, uma extensão da midiatização do religioso. O advento de novos aparatos tecnológicos, digitais e em rede, inaugura novas formas de mediações religiosas que ultrapassam a mera dimensão utilitária e instrumental, são espaços para serem ocupados a fim de "desprivatizar" ainda mais o religioso. Assim, essas mídias não devem ser consideradas como simples ferramentas de anúncio, proselitismo ou disseminação das boas novas, mas como constituidoras de uma nova ecologia comunicacional e parte integrante da cultura atual, se inserindo no contexto do pluralismo religioso, ampliando-o e potencializando-o.

As redes evidenciam não a crise da secularização, mas a sua reconfiguração, o incremento da complexidade das suas inter-relações. Vivemos em uma sociedade plural na qual as religiões tradicionais devem disputar clientelas e narrativas com novos movimentos religiosos ou mesmo com visões laicas do mundo, o que é, evidentemente, fonte de conflitos.

Logo, as religiões tradicionais ocupam as redes de forma intensa, não apenas disseminando informações ou agregando fiéis, mas também disponibilizando diferentes experiências que podem ser vivenciadas por meio das tecnologias, além de promover ativismo político. Essa tentativa de ocupação da esfera política por religiosos no contexto brasileiro é, antes de mais nada, um sintoma da secularização, pois também se trata de uma ocupação plural no qual diversas visões de mundo e interesses competem. São movimentos de contrassecularização, mas não como algo coerente, hierárquico, mas difuso e que se articula em torno de um combate em comum e em momentos efêmeros, como uma mobilização contra ou favor de alguma lei no plano legislativo ou mesmo em uma situação eleitoral.

Quanto mais intenso o pluralismo, maior a necessidade de oferecer laços fortes de engajamento em torno de um combate ou gosto em comum. Assim, um dos paradoxos da nossa época é que a mesma ambiência tecnológica que permite a tomada da palavra por diferentes minorais em busca da conquista de direitos, em um claro e inegável movimento de secularização da sociedade, permite igualmente 
a organização horizontal e polimórfica de movimentos religiosos reacionários que usam as redes não somente para disseminação de conteúdo religioso e moral, mas também para a construção de vínculos, em um processo de convergência entre a comunicação e a comunhão pela via tecnológica. Jair Bolsonaro se beneficiou dessas complexidades, servindo de ícone dessa onda conservadora. Essa comunhão ocorre em torno das pautas e da agenda de costumes que forja um patrimônio afetivo e emocional compartilhado que abastece de sentido os participantes dessas verdadeiras bolhas tecnológicas, cada vez mais fortalecidas em face de um mundo caótico e ameaçador.

\section{REFERÊNCIAS}

AGUIAR, C. E. S. A sacralidade digital: religiões e religiosidades na época das redes. São Paulo: FAPESP : Annablume, 2014.

ALMEIDA, R. D. Bolsonaro presidente: conservadorismo, evangelismo e a crise brasileira. Novos estudos CEBRAP, v. 38, n. 1, p. 185-213, abr. 2019.

BAUDRILLARD, J. Écran total. Paris: Editions Galilee, 1997.

BERGER, P. A dessecularização do mundo: uma visão global. Religião e sociedade, v. 21, n. 1, p. 9-23, 2001.

BERGER, P. L. O Dossel Sagrado. São Paulo, SP: Paulus, 2011.

CASANOVA, J. Public religions in the modern world. Chicago: University of Chicago Press, 1994.

CASTELLS, M. A sociedade em rede. São Paulo: Paz e Terra, 2007.

CHEONG, P. H. Authority. In: CAMPBELL, H. (Ed.). Digital Religion: Understanding Religious Practice in New Media Worlds. [s.l.] Routledge, 2012.

CUNHA, M. D. N. Os processos de midiatização das religiões no Brasil e o ativismo político digital evangélico. Revista FAMECOS, v. 26, n. 1, p. 30691, 19 ago. 2019.

CUNHA, M. DO N. Do púlpito às mídias sociais: evangélicos na política e ativismo digital. Curitiba: Editora Prismas, 2017. 
GOMES, P. G. Da igreja eletrônica à sociedade em midiatização. São Paulo, SP, Brasil: Paulinas, 2010.

HERVIEU-LÉGER, D. La religion en mouvement: le pélerin et le converti. Paris: Flammarion, 1999.

HØJSGAARD, M. T.; WARBURG, M. Religion and cyberspace. London; New York: Routledge, 2005.

LAWTHER, S. What is "on": an exploration of iconographical representation of traditional religious organizations on the homepages of their websites. In: Exploring religion and the sacred in a media age. Theology and religion in interdisciplinary perspectives series. Farnham, England ; Burlington, VT: Ashgate, 2009.

MAFFESOLI, M. La transfiguration du politique: la tribalisation du monde postmoderne. Paris: La Table Ronde, 2002.

MARIANO, R. Expansão e ativismo político de grupos evangélicos conservadores: secularização e pluralismo em debate. Civitas - Revista de Ciências Sociais, v. 16, n. 4, p. 708, 31 dez. 2016.

MARIANO, R. Laicidade à brasileira. Católicos, pentecostais e laicos em disputa na esfera pública. Civitas - Revista de Ciências Sociais, v. 11, n. 2, 2011.

MARTINO, L. M. S. Midiatização da religião e secularização: pensando as práticas religiosas no ambiente das mídias. PAULUS: Revista de Comunicação da FAPCOM, v. 1 , n. 1, p. 97, 16 jan. 2017.

PRANDI, Reginaldo; DOS SANTOS, Renan William; BONATO, Massimo. Igrejas evangélicas como máquinas eleitorais no Brasil. Revista USP, n. 120, p. 43-60, 2019. STEPAN, A. The Multiple Secularisms of Modern Democratic and NonDemocratic Regimes. Rochester, NY: Social Science Research Network, 2010.

TAYLOR, C. O que significa secularismo? In: MARTINEZ, B.; PEREIRA, T. (Eds.). . Esfera pública e secularismo: ensaios de filosofia política. Rio de Janeiro: Edurj, 2012. p. 157-195.

VATTIMO, G. La società trasparente. Milano: Garzanti, 2011. 